\title{
Las posibilidades del giro biográfico. Una propuesta analítica para construir perfiles de mujeres de la izquierda mexicana de la primera mitad del siglo XX
}

\author{
The possibilities of the biographical turn. \\ An analytical proposal for constructing profiles of women of Mexico's left of \\ the first half of the $20^{\text {th }}$ century \\ VERÓNICA OIKIÓN SOLANO \\ El Colegio de Michoacán (México) \\ http://orcid.org/0000-0003-4288-9541 \\ voikions@gmail.com
}

\section{RESUMEN}

En el artículo esclarezco los entrecruzamientos de los campos de la historia de las mujeres y de las relaciones de género, la historia de las izquierdas y la historia emocional. Todo con el propósito de contribuir con un modelo argumental para dar consistencia al giro biográfico que contiene en su esencia la disciplina social. Mi intención es proyectar el vuelco biográfico como la posibilidad analítica en la edificación de perfiles femeninos de la primera mitad del siglo XX, que debido a su género y a su filiación de izquierda han quedado en los márgenes de una historiografía predominantemente masculina, relegándolas a un persistente olvido. No se podrá comprender su ethos revolucionario si sólo se atiende de manera singular y en solitario a un personaje femenino, por más que haya tenido un gran carisma, liderazgo y agencia. Por ende, planteo que los ambientes individuales pueden construirse a partir de los escenarios colectivos femeninos, pues alimentan la trayectoria de una vida. Además, la indagación biográfica se complejiza al insertar los repertorios emocionales, y si dilucidamos sentimientos es posible también amplificar el espectro heurístico del campo biográfico.

Palabras clave: perfiles de mujeres de izquierda, propuesta analítica, giro biográfico, historia de las mujeres y de las relaciones de género, historia de las izquierdas, historia de las emociones.

\footnotetext{
Abstract

In this article I set out to clarify the intersections among the fields of the history of women and gender relations, the history of Mexico's left and emotional history, in order to propose an argumentative model that seeks to give consistency to the biographical turn which contains, at its core, the social disciplines. My intention is to project the biographical turn as an analytical possibility for constructing profiles of women of the first half of the $20^{\text {th }}$ century who, due to their gender and
} 
leftist affiliation have been pushed to the margins of a predominantly masculine historiography, relegated to permanent oblivion. We will be unable to understand their revolutionary ethos if those women are studied individually as solitary female figures, though they may have had great charisma and exercised leadership and agency. I suggest that constructing individual milieus based on collective feminine scenarios will nourish analyses of their life trajectories. Finally, biographical inquiries of this kind will gain complexity as we insert emotional repertories and elucidate sentiments that will allow a broadening of the heuristic spectrum of the field of biography.

Keywords: profiles of leftist women, analytical proposal, biographical turn, history of women and gender relations, history of Mexico's lefts, history of emotions.

\section{PLANTEAMIENTO INICIAL}

En las últimas décadas hemos venido constatando un florecimiento de la historiografía biográfica y se ha revalorizado su trascendencia cognitiva. ${ }^{1}$ El llamado giro biográfico -la vuelta al sujeto individual-, revitalizado con gran fuerza teórica y metodológica, ha dejado atrás la hechura de la biografía anacrónica que apelaba al panegírico de las magnas obras realizadas por los grandes personajes o héroes de la historia.

Mi propósito es elucidar analíticamente las conexiones de los campos de la historia de las izquierdas, la historia de las mujeres y de las relaciones de género y la historia de las emociones; con la finalidad de aportar argumentos modélicos para amplificar la disciplina biográfica que contiene en su esencia el campo social.

El objetivo, en este caso en particular, es que la reconfigurada tendencia biográfica nos pueda revelar los modos y el oficio para afrontar el fundamento de siluetas femeniles de la primera mitad del siglo XX, que debido a su género y a sus afinidades de izquierda quedaron relegadas y en el olvido en la historia mexicana.

Aquí cabe acotar que el siglo XX trajo nuevos vientos de cambio y transformación social. No sólo en México - con la hecatombe de la Revolución-, también en otros contornos occidentales del planeta, que atestiguaron la nueva centuria como «el siglo de las mujeres», pues «multiplicó los perfiles de la ciudadanía y los cauces de participación en la esfera pública, renovó las relaciones sociales de clase y de género, incidió en las agendas reivindicativas, potenció las asociaciones, las redes cívicas y los movimientos de mujeres». ${ }^{2}$ Todo ello marcó ineludiblemente a miles de mujeres en su ánimo íntimo y en su vida personal, familiar y social.

1 Hernández Sandoica, E.: Tendencias historiográficas actuales. Escribir historia hoy. Akal, Madrid, 2004, (Serie Historia Contemporánea), 401.

2 Muñoz Fernández, A. y Ramos Palomo, Ma D.: «Mujeres, política y movimientos sociales. Participación, contornos de acción y exclusión», en Borderías, C., coord.: La Historia de las Mujeres. Perspectivas actuales. Asociación Española de Investigación en Historia de las Mujeres e Icaria editorial, Barcelona, 2009, (Historia y Feminismo, 2), 84. 
A la luz de esta consideración destaco que a la fecha existe un reto importante para las biógrafas y biógrafos que pretendan solventar el enorme vacío historiográfico en lo referente a los núcleos femeniles adscritos a las corrientes de izquierda en México, primordialmente, aquéllos que adhirieron a las filas comunistas.

Como bien apunta la historiadora Isabel Burdiel, el hecho de asumirse como biógrafa o biógrafo pasa ineludiblemente por la asunción de una postura y un análisis en clave poliédrica, como puede ser

\begin{abstract}
su capacidad para construir y argumentar la significación histórica de una vida individual; la ampliación y reformulación de las nociones de individuo y sujeto histórico; la problematización de las nociones de experiencia, identidad, subjetividad, representatividad, privada y pública. A ello habría que añadir [...] otras cuestiones cruciales relativas a las técnicas argumentativas y los recursos expresivos de la narración/narraciones biográficas; el problema de las relaciones entre el tiempo histórico y el tiempo individual y, últimamente, el papel estratégico que puede desempeñar la perspectiva biográfica en el desafío de la llamada historia global a las fronteras nacionales y a los marcos cronológicos convencionales. ${ }^{3}$
\end{abstract}

A lo anterior, podría yo agregar que la escritura biográfica sobre mujeres tendría que sacar a flote sus vidas (es decir, extrayéndolas de los sótanos de la historia y poner en perspectiva su origen familiar, su estatus social, su templanza personal, etcétera), remarcando sus valías (en singular y en colectivo). Ello contribuiría a eliminar su sempiterna invisibilidad, haciendo constar su prolongada desigualdad en ámbitos con predominancia masculina; incluso, en los círculos de izquierda, que paradójicamente reconocieron que su época era un periodo destacado en la construcción del socialismo en México.

A la vez, la edificación de una biografía debería poner de relieve la tensión (y a la vez los enlaces) de las distintas rutas explicativas e interpretativas, para mostrar y demostrar que las vidas de las féminas de izquierda pueden asomarse a las ventanas de la historia, mediante la prosecución de una urdimbre biográfica colectiva; y a su vez poder concretar su cartografía.

Es decir, no se definirá el ethos revolucionario de los contingentes femeniles si sólo se siguen las huellas de un personaje femenino en solitario, por más que haya tenido un gran carisma, liderazgo y agencia. Planteo, entonces, que las atmósferas biográficas individuales pueden construirse a partir de los afluentes y los proscenios colectivos femeninos, pues alimentan decisivamente la trayectoria de una vida; $y$, a la vez, esa existencia femenil singular, al ir fortificando su perfil, aporta una sustancia invaluable (como parte

3 Burdiel, I.: «¿Qué Biografía para qué Historia? Conversación con Isabel Burdiel y María Sierra», en Gallego, H. y Bolufer, M. coords.: Y ahora qué. Nuevos usos del género biográfico. Icaria editorial, Barcelona, 2016, (Historia y Feminismo, 10), 30. 
de su propia historicidad $)^{4}$ para el conocimiento de las redes de izquierda en las que está inmersa, y de su ideario social, y de los que ella misma hace parte como activista, militante y copartícipe material e intelectual. ${ }^{5}$

El desafío que nos pone por delante la piedra de toque del giro biográfico es notablemente complejo, si además de todo lo que se ha indicado líneas arriba deseamos incorporar el acento emocional. La indagación histórica biográfica se complejiza a la hora de insertar los repertorios de amor, desesperación, euforia, desilusión y odio de las y los individuos; esta dimensión de subjetivación personal e íntima podría agregar otros elementos analíticos para intentar descifrar el caudal emotivo que le da fuerza a la acción individual y colectiva. El accionar colectivo a la vez plantea la manera en que podemos definir a esos núcleos femeninos como comunidades emocionales, y a cada una de sus integrantes como agentes emotivos y vitales que impulsan ideas de cambio y revolución; singulares cada una de ellas en su esencia de vida, pero a la vez como parte cardinal del conglomerado femenil revolucionario. Al dilucidar sentimientos personales y colectivos es posible también ensanchar el espectro heurístico del campo biográfico.

Todas estos fundamentos son relevantes para asentar argumentalmente que: «la fusión de vida y obra de un[a] biografiado[a] como un continuum, un todo inseparable», ${ }^{6}$ es lo vivido y lo producido por y en la existencia de una vida, «y si algo ha aprendido el feminismo a través de los años es que no todas las mujeres son iguales, y que la categoría de mujer no es única». ${ }^{7}$

Finalmente, historizar una vida representa romper en definitiva con la camisa de fuerza que durante largo tiempo acompañó a esa visión limitada de la biografía tradicional con la exaltación de figuras de poder relevantes como únicos protagonistas de la historia. Superada ésta, actualmente la dimensión científica del enfoque biográfico subraya su transversalidad, pues delinea vínculos entre campos disciplinares y abre la puerta a hipótesis innovadoras y profundas. Por tanto, mi propuesta revisionista apela al tono renovador que plantea François Dosse: «Entre historia y ficción, entre periodismo e historia, el hecho de buscar los mil y un ángulos de la existencia humana es el alimento del biógrafo que disfruta de todas las huellas de las que pueda disponer para responder al enigma que plantea el sentido de la vida». ${ }^{8}$

4 Hernández Sandoica acota que la historicidad «tiene que ver con su consideración de lo masculino y lo femenino, no ya de partida sino al contrario, de llegada. Ningún ser humano está constituido de antemano como sujeto psíquico ni como sujeto sexuado, sino que es resultado de una historia, de un marco intersubjetivo que establece unos hitos». Hernández Sandoica, op. cit., 416.

5 Concuerdo con la afirmación de la historiadora Mercedes Vilanova Ribas, quien asegura que: «las biografías permiten construir qué es lo colectivo y qué es lo personal», en «Debate. Mesa Redonda: Vidas contadas. Biografía e Historia Oral», en Gallego, H. y Bolufer, M. coords., op. cit., 255.

6 Hernández Sandoica, op. cit., 414.

7 Chassen-López, F.: «Biografiando mujeres: ¿qué es la diferencia?», Secuencia, revista de historia y ciencias sociales, Instituto de Investigaciones «Dr. José María Luis Mora», núm. 100, México, eneroabril de 2018, 147.

8 Dosse, F.: El arte de la biografía. Entre historia y ficción. Departamento de Historia de la Universidad Iberoamericana, México, 2007, (El Oficio de la Historia), 102. 


\section{LAS MUJERES DE LA IZQUIERDA MEXICANA: PROPONIENDO NODOS PARA SU TRAMA HISTÓRICO BIOGRÁFICA}

Al imponerme hace tiempo el reto de realizar la biografía de María del Refugio García Martínez (conocida como Cuca García), ${ }^{9}$ comprobé que en la historiografía mexicana existe una carencia (y silencio) en torno a las mujeres de la izquierda como agentes revolucionarias y sujetas políticas.

La historiografía desde la visión comunista, así como aquélla generalista sobre la izquierda en México, silencian a quienes fueron sus seguidoras, debido a que los relatos han sido construidos por varones, con referencias a lo público como inherente a los hombres, a lo masculino, y en donde no hay espacio para explicar la actuación femenil; se les suprime, sin ser reconocidas como actoras de la historia. Aunque la excepción al respecto fue el estudio precursor e innovador realizado por la historiadora comunista Natura Olivé en 1991, como tesis de grado y publicado muchos años después. ${ }^{10}$ Olivé procuró alejarse de los silencios y estereotipos masculinos de sus camaradas varones con respecto a sus compañeras de partido, y con una metodología de género reconoció que:

Cuando se habla del PCM [...] la presencia de la mujer nunca se hace visible. Ocasionalmente se mencionan algunos nombres, pero no como una manera de mostrar la actividad de la mujer, ni tan siquiera su presencia dentro de la organización, sino por simple casualidad [...]. En el interior de la organización partidaria la presencia de la mujer se ve poco. ${ }^{11}$

Ante este escenario, pretendo lograr que el coro femenil ensombrecido pase a la primera línea del escenario histórico de las mujeres en México para develar, comprender y explicar sus dilemas, sus resistencias, sus encrucijadas, y, en suma, su riqueza social femenina incontrovertible. Para destacar las vidas singulares e indagar en ellas es menester, como ya he planteado líneas arriba, realizar un enlace, un entrecruzamiento de correlaciones vitales que no sólo nos asegure moldear el estatus individual deseado, sino que al mismo tiempo nos auxilie metodológicamente en la construcción de otros más.

La intención final es revalorar la construcción biográfica para rebatir estrechas posturas historiográficas que todavía hoy en día se cuelan por las ventanas académicas:

Ser biógrafo era algo así como ser novelista frustrado o, como quien dice, un historiador de poca monta. 'Esas son cosas de gente poco seria', se decía a modo de burla

9 Oikión Solano, V.; Cuca García (1889-1973), por las causas de las mujeres y la revolución. El Colegio de Michoacán y El Colegio de San Luis, prólogo de Mary Kay Vaughan, Zamora, 2018, (Colección Investigaciones), passim.

10 Olivé, N.: «Las mujeres en el Partido Comunista Mexicano. Los años treinta». Tesis de maestría en Historia, Escuela Nacional de Antropología e Historia, División de Estudios Superiores, Programa de Maestría en Historia y Etnohistoria, México, 1991. Se publicó bajo el título Mujeres Comunistas en México en los años treinta. Ediciones Quinto Sol, México, 2014.

11 Olivé, Mujeres Comunistas en México en los años treinta, 17 y 68. 
entre los historiadores profesionales de aquí y allá. Sin embargo, la tentación por lo biográfico no dejó de persistir. Como si se tratase de un pecado irresistible, nunca faltó el historiador que sucumbiera al acto de biografiar. Tales han sido las filias y las fobias que ha despertado este género, que pese al menosprecio que soportó durante la última centuria, hoy está de regreso con una vitalidad que coloca su práctica en el centro de las corrientes historiográficas más innovadoras. ${ }^{12}$

Por todo lo dicho, mi pretensión es alentar el rescate de figuras como las de Estela Carrasco, Esther Chapa, Esperanza Balmaceda, Luz Ardizana, Luz Encinas, Angélica Arenal, Fidelia Brindis, Margarita Gutiérrez Velasco, Julia Barradas Hernández, Elodia Cruz, Elisa Zapata Vela, Dolores Núñez, Dolores Uribe, Dolores Sotelo, Luz Ofelia Guardiola, Esthela Jiménez Esponda, Agustina Oliva y muchas más. ${ }^{13}$ Todas entrelazadas entre sí porque formaron parte de una ola generacional vanguardista en las luchas sufragistas y por el reconocimiento pleno de los derechos civiles, políticos y de ciudadanía y, por supuesto, en la defensa del ideal revolucionario; recuérdese que su generación absorbió las influencias radicales de la Revolución mexicana, enhebradas con el pensamiento socialista e identificadas con el imaginario proveniente de la Revolución Bolchevique.

Este engarce de lo individual con lo colectivo asienta una metodología nodal, es decir, que los nodos o categorías nodales que propongo funjan como guías analíticas para proceder, en primera instancia, al acercamiento biográfico de una individua o actora. Revelar, hasta donde sea posible, su esencia vital y sus relaciones e interconexiones culturales y sociopolíticas. Pero que a la vez, aquellos nodos o puntos nodales sean un

12 Pereira Fernández, A.: "Notas para jugar con la ilusión biográfica y no perderse en el intento", Revista Científica Guillermo de Ockham, vol. 9, núm. 1, Universidad de San Buenaventura, Cali, Colombia, enero-junio de 2011, 121-122.

13 Del conjunto femenil de izquierda, han sido atendidas en mayor o menor medida sólo algunas pocas, como Concha Michel, Tina Modotti, Benita Galeana, Consuelo Uranga y Adelina Zendejas. Los relatos biográficos son muy desiguales en cuanto a la calidad de la narrativa del género. Anoto sólo algunos ejemplos: Poniatowska, E.: Tinísima. Ediciones Era, México, 1992; Cano, G.: «Adelina Zendejas: arquitecta de su memoria», Debate feminista, año 4, vol. 8, septiembre de 1993, 387-400; Olcott, J.: «Take off that Streetwalker's Dress. Concha Michel and the Cultural Politics of Gender in Postrevolutionary Mexico», Journal of Women's History, núm. 3, vol. 21, 2009, 36-59; Vargas Valdés, J.: Consuelo Uranga. La roja. Nueva Vizcaya editores, Chihuahua, 2017; González Bustos, M.: Historia de una mujer comunista. Benita Galeana Lacunza. Universidad Autónoma Chapingo, México, 2017. Susie Porter ha caracterizado la figura de Otilia Zambrano, quien en un periodo corto de su vida militó en el PCM. Porter, S.: «Otilia Zambrano Sánchez de García, cambio generacional y activismo en las décadas de 1920 y 1930», en Lau Jaiven, A. y Mc Phail Fanger, E. coords.: Rupturas y continuidades. Historia y Biografías de Mujeres. Universidad Autónoma Metropolitana Unidad Xochimilco, México, 2018, 171-197. Yo misma me he empeñado en recuperar las historias de vida de Mathilde Rodríguez Cabo y Graciela Amador. Véanse: Oikión Solano, V.: «Un atisbo al pensamiento y acción feministas de la doctora Mathilde Rodríguez Cabo», Relaciones. Estudios de historia y sociedad, núm. 149, vol. XXXVIII, invierno de 2017, 101-135. Oikión Solano, V.: «En favor del ariete infantil. La praxis socialista de Graciela Amador y su función pedagógica. Los años posrevolucionarios», conferencia impartida en el Seminario Permanente de Investigación Historia de las Infancias. Problemas y perspectivas, Facultad de Historia de la Universidad Michoacana de San Nicolás de Hidalgo, Morelia, 16 de enero de 2020. 
peldaño hermenéutico - de crítica e interpretación- para escalar a un segundo nivel de complejidad, eslabonando y entrecruzando, transversalmente, series o conjuntos biográficos mediante operaciones intelectivas que nos conduzcan a unir y a vincular entre sí a los conglomerados de las izquierdas femeniles.

No sólo con la idea delimitada, que puede ser válida, de una prosopografía de revolucionarias de la primera mitad del siglo XX mexicano, sino para producir de manera efectiva una biografía del género mujer, ${ }^{14}$ como la ha definido Susanna Tavera con una explicación muy fina y conceptualmente rica. Y, por supuesto, para enfrentar el enorme «desafío que produce el reconocimiento de que las fuerzas de la vida individual y las fuerzas de la vida colectiva son indisociables, [y] se desarrollan unas dentro de las otras». ${ }^{15}$ Sin perder de vista la tensión siempre recurrente entre lo individual y lo social, pero que puede expresarse de manera explícita y resolverse mediante la aproximación biográfica.

Este reto biográfico complejizado significa establecer los fundamentos de la historia en clave femenina, precisamente con un sesgo de género, necesariamente intrincada y diversa, para la exploración de las identidades, las subjetividades, el discurso y la representación social, así como la agencia, las prácticas y las rutinas políticas.

Todo ello implica penetrar en el espíritu femenino individual más íntimo en el tono clásico propuesto por Carlyle: «ver en su interior, entender sus expresiones, descifrar el corazón absoluto de su misterio». ${ }^{16} \mathrm{Y}$, a la par, de forma determinante, insertar esa trayectoria de vida en su colectividad femenil con un enfoque transnacional, pues sus decisiones personales y en colectivo -que impulsaron nuevas mentalidades y formas culturales conforme avanzaba el siglo $\mathrm{XX}$, como fue el caso de la paradigmática new woman-apostaron, muchas veces a contracorriente, al cambio de su propia existencia y a la transformación del orden patriarcal de las estructuras sociales.

Y, en ello, el feminismo igualitario fue muy alentador como plataforma para plantear la igualdad frente a las inequidades de género, y tuvo el gran reto de concretar en la realidad cotidiana, en el caso de las mujeres mexicanas, esa aspiración de igualdad, una igualdad militante que abrevó de sus orígenes revolucionarios; pues muchas de ellas tuvieron una experiencia de guerra antecedente que las marcó, indeleblemente, al integrarse de distintas formas a la lucha armada en el movimiento revolucionario de 1910. El tránsito de sus vidas en medio de la violencia política también las trastocó emocionalmente.

Sin olvidar, en ningún momento, el abigarrado contexto de la posrevolución mexicana -no ha de desecharse en ningún caso el potencial de la reconstrucción contextual

14 La historiadora Susanna Tavera hace una llamada de atención acerca de la prosopografía clásica y el género biográfico de mujeres: «Las diferencias obedecen a que en las formas más comunes de prosopografía las biógrafas o los biógrafos no acostumbran a afrontar colectivos tan 'obscuros' o invisibles como los de las mujeres ideológicamente invisibilizadas». Tavera, S.: «¿Escribir sobre una vida o sobre muchas? Vida, escritura e historia: la política de las biografías de mujeres», en Gallego, $\mathrm{H}$. y Bolufer, M., coords., op. cit., 165.

15 Burdiel, I., ed.: «Presentación» dossier «Los retos de la biografía», Ayer, núm. 93 (1), $2014,14$.

16 Carlyle, T.: Biografía. UNAM, México, 2006, (Colección Pequeños Grandes ensayos), 11. 
como apoyo para el relato biográfico- con vertiginosos cambios en la cultura política, que permearon a las sociedades de su tiempo y afectaron desde luego a las mujeres en general, y, específicamente, a los cuadros femeniles comunistas y a mujeres de izquierda sin militancia política formal. Esos núcleos femeniles -generalmente de capas medias urbanasenarbolaron el ideal de remodelación social impregnado de las tradiciones políticas del radicalismo de la revolución de origen liberal jacobino y anarcosindicalista.

Pero no sólo eso, además, debieron lidiar con el machismo de sus cúpulas partidistas y, a la vez, guardar lealtad y disciplina a sus líneas estratégicas y principios programáticos, pues antes de poder postular y debatir sobre su condición y demandas de género al interior de su formación política, se les incitaba a definirse y se les conceptuaba como cuadros preparados para luchar por la instauración de la dictadura del proletariado.

Aunque se ha documentado cómo sus dirigencias y camaradas varones poco entendieron de las demandas puntales impulsadas por las mujeres. Michelle Perrot llama la atención sobre los discursos ideologizados en masculino, porque en la realidad los esquemas eran muy rígidos y acusaban un fuerte dogmatismo con sesgo de género: «En la teoría, que subordina la lucha de sexos a la lucha de clases; en la práctica del poder que se apoya sobre partidos, incluso sobre la dictadura de un proletariado muy masculino. Entre la virilidad del militante y el ama de casa ideal las mujeres comunistas no tienen escapatoria». ${ }^{17}$

Aquí es menester hacer énfasis en la transgresión del minúsculo núcleo femenil fundador del Partido Comunista Mexicano (PCM), en noviembre de 1919: Cuca García, Estela Carrasco, Elena Torres, Thorberg Brundin y Evelyn Trent. ${ }^{18}$ No sólo por su inicial afiliación militante, sino porque a la par constituyeron el Consejo Feminista Mexicano (CFM) (que en la historiografía ha sido abordado limitadamente), ${ }^{19}$ adherido al propio PCM como el espacio feminista innovador y fundamento primigenio en las luchas por la igualdad de las mexicanas de la primera mitad del siglo XX.

En contraste, estas mujeres y las subsecuentes integradas al partido se vieron marcadas íntima y emocionalmente en medio del intenso combate ideológico instrumentado por su organismo político, a consecuencia de la concepción partidaria acerca de que por

17 Perrot, M.: Mi historia de las mujeres, traducción de Mariana Saúl. Fondo de Cultura, Buenos Aires, 2009, (Sección de Obras de Historia), 204.

18 Oikión Solano, V.: "Las comunistas mexicanas, herederas de revoluciones", Memoria. Revista de Crítica Militante, núm. 272, año 2019-4, 19-25.

19 Revísese el capítulo 5 «Insuflando el despertar feminista rojo», de mi obra sobre Cuca García, op. cit., 78-95. Gabriela Cano y Ana Lau han documentado, en sus respectivos estudios, los desafíos de este primigenio conglomerado feminista. Cano, G.: «Las mujeres en el México del siglo XX. Una cronología mínima», en Lamas, M. coord.: Miradas feministas sobre las mexicanas del siglo XX. Fondo de Cultura Económica y Conaculta, México, 2007, 21-75. Lau, A.: «Las luchas por transformar el estatus civil de las mexicanas: las organizaciones pro sufragio femenino 1919-1930», en Cárdenas, N.: y Guerra Manzo, E. coords.: Integrados y marginados en el México posrevolucionario. Los juegos de poder local y sus nexos con la política nacional. Universidad Autónoma Metropolitana Unidad Xochimilco y Miguel Ángel Porrúa Editor, México, 2009, 297-347. 
fuera de sus filas no había un verdadero partido de la clase obrera, como elemento central de su construcción ideológica bolchevique. Incluso, la disputa fue conducida y mediada por los propósitos centralizadores y los intereses políticos del Partido Comunista de la Unión Soviética (PCUS) y la Tercera Internacional Comunista (IC, Comintern) -conceptuada como el partido mundial de la revolución con el objetivo de extender ésta por todo el planeta.

A lo largo del tiempo esta controversia se puso de manifiesto mediante un vaivén de posiciones, virajes inesperados, declaraciones controvertidas, errores de apreciación, análisis con poco sustento y desconcierto frente a la realidad. Por lo tanto, las directrices del PCM se tornaron contradictorias, dogmáticas y sectarias con respecto a sus estrategias y tácticas de lucha contra sus enemigos políticos y de clase en tanto Sección Mexicana de la IC, y por las incongruencias en sus líneas de acción en distintas coyunturas políticas frente a los regímenes de gobierno de la revolución triunfante. ${ }^{20}$

Inevitablemente, estas alteraciones políticas impactaron en el ánimo de los cuadros femeniles, pues debieron actuar respondiendo a la línea dictada por el partido. «No podía ser de otra manera, la condición de militantes la habían elegido, la de mujer le había sido dada por azares del destino. Aquélla se imponía sobre ésta». ${ }^{21}$

De igual manera, las comunistas se vieron afectadas a la vera de las disrupciones ideológicas de las izquierdas nacionales e internacionales, como el giro a la izquierda y el arranque del tercer periodo propugnado por el sexto Congreso de la IC (julio de 1928), así como por los efectos emocionales producidos a causa de la obligada clandestinidad del PCM; desde fines de los años veinte y hasta mediados de los años treinta a la que fue condenado por el bloque hegemónico en el poder.

No obstante, y a contracorriente, el impulso y la organización de los contingentes femeniles trastocaron -aunque fuese en marcos limitados- el statu quo de su entorno comunista a la vera de las sociabilidades locales y las redes internacionales establecidas por ellos mismos en el periodo de entreguerras. Lo que implicó interpelar al Estado autoritario en lo interno, con su inclusión -en el primer cuatrienio de la década del treinta- en congresos de obreras, campesinas y mujeres de clase media, entrando con más determinación en el espacio público, y a la vez debatiendo posturas ideológicas y políticas con otros sectores femeninos afines al gobierno o de raigambre conservadora. En lo externo, el conjunto femenil de izquierda y la templanza de su liderazgo abrieron mirillas para elevar demandas de género, con la consecución de asambleas y conferencias a nivel mundial; desplegaron su accionar en el contexto de los frentes populares, como estrategia cominternista; volcaron su solidaridad en la lucha antiimperialista y antifascista, con acciones, proclamas y voces muy comprometidas, y con vocación pacifista en medio del conflicto bélico mundial y los inicios de la posguerra, y a lo largo de más de tres décadas. Desde

20 Revísese: Condés Lara, E.: Atropellado amanecer. El comunismo en el tiempo de la Revolución Mexicana. Benemérita Universidad Autónoma de Puebla, México, 2015, 350 y 403.

21 Olivé, Mujeres Comunistas en México en los años treinta, 52. 
luego, también la tensión y la transgresión que están detrás de todo ello debieran ser variables primordiales a considerar en este proceso de intelección pluri biográfico. Veamos entonces con qué armas nos podemos aventurar en la hazaña biográfica.

\section{HIBRIDANDO LOS CAMPOS DISCIPLINARES PARA DAR CONSISTENCIA A LA BIOGRAFÍA DE MUJERES}

La proposición de este esquema modélico aspira a que el giro biográfico -conceptuado como «una forma de hacer historia que deviene particularmente potente gracias precisamente al entrecruzamiento con otros abordajes»- ${ }^{22}$ pueda articular una urdimbre complejizada con base en los arcos epistemológicos referidos a la historia política de la izquierda, la historia de las mujeres y de las relaciones de género y la historia de las emociones, entremezclando o entrelazando en diacronía conexiones y variables diversas (hogareñas, infantiles, juveniles, familiares, escolares, sentimentales, amorosas, vivenciales, profesionales, laborales, exiliares, sindicales, culturales, artísticas, etcétera). Con el fin de desmenuzar las actuaciones, las responsabilidades y las razones culturales, económicas y sociopolíticas de una determinada figura femenina, destacando sus experiencias, valores, creencias, convicciones, declarativas, resistencias y prácticas en función de sus opciones y militancias de izquierda. Las concatenaciones y los vínculos de todas éstas, deben ser, necesariamente, examinados con una mirada de género.

En suma, propongo que al reconstruir todas estas relaciones y sus interdependencias, poniendo de relieve la capacidad relacional femenina, tendremos la competencia para comprender cómo se constituyeron su conciencia, su imaginario y su identidad política, es decir, su ideología, pensamiento y praxis definidos por su actuación de izquierda. En esencia, instrumentalizando el engarce entre el ser social y su conciencia social. Al destilar todos estos elementos es posible delinear con bastante cercanía la plenitud de una vida marcada por el ideario del cambio social.

Debo subrayar, además, que los enfoques escogidos pueden aprovecharse como guías analíticas o nodos (a los que me he referido anteriormente), a manera de ensamblajes o utillajes necesarios para producir argumentos con rigor analítico y explicar el sentido de una vida de mujer, es decir, su vitalidad y subjetividad femeninas; asomarnos a la complejidad de su existencia -sus contradicciones, sus inseguridades y sus batallas más íntimas-; revivir su voz y sus ideas; conocer sus interpelaciones de clase más señeras; e insertarla en su contexto social y colectivo, y en los marcos institucionales de su época teñidos de no poca violencia estructural. ${ }^{23}$

22 Sierra, M.: «¿Qué Biografía para qué Historia? Conversación con Isabel Burdiel y María Sierra», en Gallego, H. y Bolufer, M., coords., op. cit., 22.

23 Burdiel asegura que: «Los cruces contextuales son fundamentales porque son los que permiten comprender las diversidades de trayectorias posibles por parte de distintos individuos, su propia conformación como 
Por ende, acentúo el giro biográfico como la posibilidad disciplinar de una historia reivindicativa, en este caso, de género. Pero a la vez, de manera destacada, como resultado de la hibridación teórica y metodológica que he planteado, y que comparto con la postura de la historiadora María Sierra, quien asienta que este original examen analítico: «relaciona historia política con historia de género e historia de las emociones, pues una vez más he preferido entender este abordaje como un enfoque transversal, compatible con otras ópticas, antes que como un campo delimitado de estudios. La biografía es el hilo rojo que ha hecho, en gran medida, posible este mestizaje». ${ }^{24}$

Diseccionemos esta mixtura, a la que yo he llamado hibridación. Aquí lo que nos interesa es establecer registros mensurables del repertorio del que podemos disponer para producir un conocimiento específico en la modulación del enfoque biográfico de mujeres.

Empecemos por franquear la historia política de la izquierda como el primer eslabón necesario para la operación de trama y urdimbre. No me extenderé en definir el concepto de izquierda; sólo apunto que en materia política dicha denominación se refiere

a las posiciones radicales 'que sustentan las opiniones contrarias a los opuestos, 1lamados de derecha, o derechas' y que hace referencia a los diputados de la Asamblea Nacional, posterior a la revolución francesa, en la que los también llamados 'jacobinos', extremistas o radicales, se sentaban de este lado -la izquierda- en el recinto parlamentario en el que se sostenían enconados debates sobre el rumbo que habría de seguir el gobierno revolucionario, posterior a la gran crisis de julio de 1789. A partir de entonces, siempre se ha dado por supuesto que se sabe bien lo que el término 'izquierda' o 'izquierdista' debe significar [...], me parece necesario señalar que en este concepto incluyo a todos aquellos sujetos que sostienen una posición antiimperialista, que se identifican con las luchas populares, con las reivindicaciones de los sectores más depauperados de la población, que se interesan por el desarrollo de los fenómenos de masas, particularmente campesinos y obreros, [...] que se oponen a una injusta distribución de la riqueza y a las formas de producción basadas en la explotación del hombre por el hombre. ${ }^{25}$

En esta caracterización no se debe olvidar la develación de su ethos, es decir, la razón (suprema) de ser de mujeres y hombres afincados en el imaginario del cambio social y su conflicto contra el Estado, y las fuerzas poderosas que detrás de él integran la oligarquía y el conservadurismo. Todo lo cual significa que aquellos cuadros militantes asumen «posturas de oposición al régimen vigente en tanto [su carácter] explotador, o

tales y, también, la necesidad de cuestionarles como sujetos unitarios y homogéneos». Revísese: Burdiel, I.: «¿Qué Biografía para qué Historia? Conversación con Isabel Burdiel y María Sierra», en Gallego, H. y Bolufer, M. coords., Ibid., 23.

24 Sierra, M.: «¿Qué Biografía para qué Historia? Conversación con Isabel Burdiel y María Sierra», en Gallego, H. y Bolufer, M. coords., Ibid., 28-29.

25 Sánchez Quintanar, A.: «La historiografía mexicana de izquierda», en Hernández, C. coord.: Tendencias y corrientes de la historiografía mexicana del siglo XX. El Colegio de Michoacán e Instituto de Investigaciones Históricas de la UNAM, Zamora, 2003, (Colección Debates), 95-96. 
representante de los intereses de la clase explotadora, y que en cada etapa histórica la izquierda puede tener propuestas diversas». ${ }^{26}$

En la historia de una mujer en específico resulta del todo congruente ligarla al denominador común del comportamiento identitario adoptado por su formación o movimiento político. Por ende, destacamos el ethos como la facultad compartida de la experiencia colectiva, intensa y profunda de izquierda. De tal manera, que la construcción biográfica femenil debe establecer y exhibir dicha experiencia, subrayando la propia trayectoria de vida y su accionar vivencial en relación con su grupo sociopolítico opositor.

Las/os historiadores que pretendan realizar una historia biográfica, desde las perspectivas de lo político y de lo social (finalmente ambas confluyen y se combinan en los acontecimientos reales, y así debemos describirlas y analizarlas) han de dejar atrás las viejas concepciones de la historia unilineal, vista como la enumeración de faustuosos hechos militares, la exaltación de los grandes hombres que conducen a las masas y tienen en sus manos el viraje de la historia, o, incluso aquélla que concentra únicamente su mirada en reinas y emperatrices para alabar sus particulares dotes.

Es de sobra reconocido que no podremos comprender la esencia de los fenómenos históricos, y, específicamente aquéllos protagonizados o en los que está inmersos una figura histórica, si no echamos mano de un bagaje analítico e interpretativo heterogéneo y amplio, pero consistente, apoyándonos incluso en otras ciencias sociales. De lo cual se desprende que podemos acercarnos a procesos históricos - y de manera concreta al devenir de un determinado personaje- mediante instrumentos teóricos y metodológicos de carácter interdisciplinario, y lo subrayo como una forma de aproximación gnosiológica.

Es bien cierto que los intercambios disciplinares sostenidos por la historia con la ciencia política -sin faltar la revisión de la historia de las ideas políticas-; la sociología histórica; la antropología, la etnología y la etnohistoria; la economía -de manera preponderante las vertientes económicas de la historia-; la filosofía; la psicología social, y hasta con el psicoanálisis, han fructificado en un sentido totalmente innovador, y no son pocas/ pocos las/os historiadores -sobre todo los europeos y estadounidenses- que le han sacado «jugo» a esa relación, intentando, bajo una óptica más enriquecedora, construir nuevas interpretaciones del pasado cercano o lejano.

A la fecha existe consenso en torno de la renovación interpretativa en los campos de la historia política y la historia social, pues se han redoblado esfuerzos historiográficos a base de consideraciones analíticas para vertebrar modelos que nos asistan en explicaciones más densas, plausibles y originales. Orientadas, por ejemplo, «a pensar y descifrar las claves descriptivas y explicativas bajo las que se resuelven los modos de cambio y los modelos de transición cultural que afectan a las mujeres en el campo de la política y del poder». ${ }^{27}$

\footnotetext{
26 Ibid., 96.

27 Muñoz Fernández, A. y Ramos Palomo, Ma D.: «Mujeres, política y movimientos sociales. Participación, contornos de acción y exclusión», en Borderías, C., coord., op. cit., 105.
} 
En el marco del giro biográfico, de manera específica, para dilucidar forma y fondo de un perfil femenino, es menester acopiar distintos registros, como la caracterización del Estado y el análisis del poder formal y las maneras de su ejercicio en relación directa con determinado personaje y su entorno político y comunitario. Seguidamente, se podrá calibrar el alcance y las huellas políticas de una figura en el entramado e impulso de su propio empoderamiento formal e informal.

A la par, se requiere la indagación, desde un enfoque de género, de la estructura social y la lucha de clases. Así como de los movimientos sociales. Aunque, específicamente, debemos llamar la atención acerca de la denuncia de «que la propia definición dominante de política ha excluido de los análisis a movimientos con alta participación femenina y en general, las investigaciones han mostrado poco interés por la militancia de las mujeres». ${ }^{28}$

Aquí es menester enfocar la contribución individual femenina en la esfera pública -poniendo en evidencia su participación y acción directa «en el sentido topográfico, político y simbólico del término»-, ${ }^{29}$ es decir, su accionar personal y determinado en todo tipo de movilizaciones. Por ejemplo, haciendo un uso político de la calle como protagonista de huelgas, manifestaciones, protestas, revueltas, concentraciones, marchas callejeras. Atendiendo de igual manera su involucramiento personal en las estrategias y tácticas operacionales de su organismo político, con la finalidad de interpelar al poder público, insuflar el desorden político y, eventualmente, acceder a la toma del poder.

Otros registros son igualmente relevantes: las sociabilidades políticas establecidas desde la izquierda femenil con liderazgos populares del campo y la ciudad (lo que hace evidente la solidaridad individual y de grupo, y el internacionalismo proletario, con organismos de la sociedad civil y con asociaciones sindicales mixtas o femeninas en demanda de mejores condiciones laborales y sociales). La propaganda política y la divulgación del ideario político - puestos en marcha en el espacio público por conjuntos femeniles, portando emblemas como las banderas rojas, y alzando su voz con cánticos revolucionarios, significativamente entonando «La Internacional»-; y pregonando declarativas socialistas y comunistas, así como la calidad de su difusión en el entorno social; pero sobre todo el impacto en la mentalidad y en el acrecentamiento de la conciencia de la(s) activista(s). La hechura de la prensa de y para mujeres (son los casos de La Mujer, primera época, periódico bimensual publicado fugazmente en enero de 1920; su segunda época constó probablemente, no se tiene certeza, de seis números, entre el 15 de mayo de 1921 y hasta marzo de 1922. Y de Mujer Trabajadora, revista mensual de agosto de 1934 a julio de 1935), como formadoras de opinión pública femenil, ${ }^{30}$ con la actuación destacada

28 Martínez Hernández, E.: «Las formas de acción colectiva: partidos políticos y movimientos sociales», en Lois, M. y Alonso, A. coords.: Ciencia política con perspectiva de género. Akal, Madrid, 2014, (Akal Textos, 38), 151.

29 Muñoz Fernández, A. y Ramos Palomo, Mㄹ.: «Mujeres, política y movimientos sociales. Participación, contornos de acción y exclusión», en Borderías, C., coord., op. cit., 80.

30 La Mujer fue publicado por la directiva del Consejo Feminista Mexicano. El número 2 (jueves 29 de enero de 1920) de la primera época se localiza en el Archivo Histórico del Centro de Estudios del 
de figuras hasta ahora desconocidas, y cuyas labores informativas especializadas actúan como verdaderas plataformas para impulsarlas como mujeres de acción, que se hacen y se constituyen a sí mismas.

Y el papel de todos estos componentes en la recreación de una presencia política femenil, de talante transgresor y revolucionario; con un bagaje bien apuntalado en una cultura de la movilización de la izquierda opositora, y la concreción de lo que se ha conceptuado como una «identidad política femenina». ${ }^{31}$ Mediante esta vía se pueden visualizar y resaltar, en distintas coyunturas, las figuras femeninas que plantearon lúcidamente la ruta de los cambios políticos y la transformación de la sociedad con una agencia muy sólida.

Con todo ello podemos impulsar reconstrucciones historiográficas renovadas y estudios de caso originales para poner el acento en sujetas históricas que han pasado desapercibidas en las antiguas tónicas de una historia política tradicional:

Las mujeres participábamos en la lucha general, hacíamos lo mismo que los hombres, repartíamos propaganda, íbamos a las fábricas a hablarles a los obreros. Íbamos a [la fábrica] La Consolidada, a [la fábrica] Clemente Jacques, a los Ferrocarriles. Que se va a hacer un mitin en tal parte, pues vamos a ayudar, aunque sea a gritar, aunque sea a pedir. Íbamos a los mítines, a las reuniones, cantábamos, luego nos agarraba la policía, y...a la cárcel. Íbamos a manifestaciones. El primero de mayo éramos las primeras, al frente íbamos. ${ }^{32}$

Por ende, la combinación, y el enlace de ese inventario político, devienen campos de estudio primordiales para comprender la esencia del contrapunto dialéctico desigual entre mujer, Estado y revolución, pues la movilización femenil -a lo largo de la media centuria- estuvo mediatizada constantemente por el no reconocimiento jurídico de sus derechos políticos y sociales plenos, lo que en los hechos significó cortapisas a sus aspiraciones políticas y freno a la organización del conglomerado femenil de izquierda. En sustancia, queda al descubierto el desigual reparto de poder y de reconocimiento de derechos entre mujeres y hombres.

Aquellos registros, además, nos serán de suma utilidad para biografiar una determinada existencia que, en el caso mexicano, asumió una tradición de lucha pues formó parte

Movimiento Obrero y Socialista, A.C. (en adelante AHCEMOS), Fondo Mujeres (1920-1979), caja 1, folder 000016. Otro ejemplar del mismo número se ubica en el Fondo documental Isaac Arriaga de la Biblioteca «Luis Chávez Orozco» del Instituto de Investigaciones Históricas de la Universidad Michoacana de San Nicolás de Hidalgo (Morelia, México); la segunda época de La Mujer se encuentra en el archivo personal de la doctora Gabriela Cano. Y Mujer Trabajadora fue editada por la Comisión Permanente del Segundo Congreso de Obreras y Campesinas (noviembre de 1933). Los ocho números publicados se resguardan en el AHCEMOS (sin clasificación). En ambas publicaciones tuvo intervención de liderazgo Cuca García.

31 Muñoz Fernández, A. y Ramos Palomo, M ${ }^{a}$ D.: «Mujeres, política y movimientos sociales. Participación, contornos de acción y exclusión», en Borderías, C., coord., op. cit., 77.

32 «Testimonios de Margarita Gutiérrez Velasco, Angelina García Ponce y Julia Barradas Hernández», en Olivé, Mujeres Comunistas en México en los años treinta, 28. 
de una generación compelida a destruir el antiguo régimen dictatorial de Porfirio Díaz, y a construir una alternativa de izquierda como parte de un proyecto de nación aspirante a profundizar en las reformas establecidas en la Carta Magna de 1917.

La mujer como mujer, aún no disfruta de aquellas conquistas que ya están hechas ley. La razón fundamental es la falta de compañerismo de los hombres para facilitar el desenvolvimiento de la mujer en el terreno sindical y campesino. Cuando participa en una manifestación, en un mitin o a un congreso campesino, se le hace objeto de chanzonetas estúpidas, que no están de acuerdo con el grado de civilización que pretendemos dar. La mujer tiene derecho al descanso dos meses antes y dos después del embarazo; a disfrutar del $75 \%$ del sueldo en caso de enfermedad, y en caso de que las empresas ocupen un $40 \%$ de mujeres, tienen el derecho de disfrutar el beneficio de una casa cuna en la cual puedan dejar a sus hijos mientras trabajan. Además, si trabajan con una empresa que ocupe más de doscientos obreros deberá tener derecho a escuela para sus hijos. ${ }^{33}$

Ello implica profundizar en la indagación de las demandas de las mujeres y sus liderazgos más esforzados y tenaces, que han permanecido invisibles y oscurecidos. Pero, a la vez, significa reconocer, de igual modo, como lo ha puntualizado la historiadora Gabriela Cano, que: «No se trata [...] de exagerar el protagonismo de las mujeres o de inventar personajes que no existieron, sino de profundizar en los procesos que construyeron la política como un espacio masculino que, por definición, excluía o desalentaba la participación femenina». ${ }^{34}$

Aquí entra en escena la historia de las mujeres y de las relaciones de género; de tal suerte que se ha de considerar como otro eslabón más para la reconstrucción biográfica. Se ha de partir de la premisa de que la irrupción de amplios contingentes femeniles en el espacio público mexicano, a lo largo de la primera mitad del siglo pasado, y otrora confinados en sus espacios hogareños (recuérdese que el orden patriarcal del liberalismo imponía el destino de cualquier mujer invocando su rol de «ángel del hogar», virtuosa, ama de casa, dueña de la economía doméstica, y, por supuesto, madre y esposa), significó «una historia de las mujeres activas, en las múltiples interacciones que originan los cambios». ${ }^{35}$

El relacionarse en lo personal y en lo colectivo supuso que el accionar de las mujeres de izquierda cuestionara de distintas maneras la ideología de la domesticidad, pues al igual que los conjuntos femeniles obreros, salieron al espacio público para ocupar plazas laborales y articular redes de apoyo. Este cuestionamiento no fue «sólo en términos económicos, al plantear una nueva división sexual del mercado de trabajo, sino también morales. No en vano el canon ético y político situó en el centro del debate ideológico la influencia del

33 «La Organización de la Mujer», El Machete, órgano del PCM, núm. 506, sábado 8 de enero de 1938, 8. Cursivas mías. Esa supuesta falta de compañerismo no se entendía como una mentalidad machista y como parte consustancial del sistema patriarcal y de suyo inequitativo para con las mujeres. 
trabajo asalariado femenino sobre la maternidad y la familia, y su posible incidencia en la virtud de las mujeres». ${ }^{36}$ En esta tesitura debemos expandir la edificación biográfica de las mujeres en su dimensión como trabajadoras, subrayando las tensiones y los dilemas personales que debieron enfrentar en un mundo laboral copado por el género masculino.

La delineación de una semblanza personal avanzará aún más si erigimos mujeres deslindadas del modelo social de género al que estaban condenadas en su época, es decir, constreñidas a una secuencia vital monótona de servidumbre y sumisión. En las mexicanas de izquierda del periodo, por ejemplo, se avistan firmes transgresoras de cartabones añejos que pretendían anular su creatividad. Sus arrestos contestatarios han dejado huellas documentales, que sólo recientemente se comienzan a valorar. Aunque se constata que sus esfuerzos no dejan de estar mediados por su praxis comunista y por la concepción de que su lucha debería realizarse a la par con sus camaradas varones:

Las conquistas alcanzadas para la mujer mexicana en la Ley Federal del Trabajo y en el Código Civil no son suficientes y sabemos que la Revolución tiene una inmensa deuda con ella; no le ha hecho justicia plena ni en el terreno económico, ni en el político, ni en el social; la sigue considerando como menor de edad y le otorga una protección precaria. Pero ya la mujer mexicana va aprendiendo por dura experiencia, que, como elemento tradicionalmente explotado, debe unirse definitivamente al movimiento emancipador de la clase proletaria. La mujer organizada en México ha demostrado ya que está en pie de lucha, alerta ante los problemas de su país y del mundo entero, consciente de sus derechos y de sus responsabilidades, compañera del hombre, para crear unida positivamente $a$ él, un mundo nuevo más justo y más humano. ${ }^{37}$

La historia social de género también nos dota de otras pautas para acrecentar nuestra proposición analítica. Tiene el gran mérito de que nos ofrece registros de la mayor envergadura, pues la podemos conceptualizar como una exploración y explicación para dilucidar las identidades de género y la conciencia de las mujeres. Y más precisamente, abarcadora de la subjetivación femenina como un proceso continuo, un acaecer en movimiento que desvela su íntimo estatus de mujer, sus maneras específicas y entrañables de comprender el mundo, y sus cavilaciones más personales, y, por supuesto, la edificación y el entramado relacional de sus funciones sociales y políticas.

Estos registros cumplimentan la especificidad social y la subjetividad femenina, y, a la vez permiten visualizar las contiendas libradas por un determinado personaje femenil en específico, pero relacionado con el conjunto de mujeres revolucionarias de las prime-

36 Muñoz Fernández, A. y M M D. Ramos Palomo, «Mujeres, política y movimientos sociales. Participación, contornos de acción y exclusión», en Borderías, C., coord., op. cit., 83.

37 Esperanza Balmaceda de Josefé, «La Mujer Mexicana ante la Revolución», diciembre 16 de 1936, en Archivo Histórico de la Unidad Académica de Estudios Regionales de la Coordinación de Humanidades de la UNAM (Centro de Estudios de la Revolución Mexicana «Lázaro Cárdenas», A.C.), Fondo documental Mathilde Rodríguez Cabo, caja 1, carpeta 13, documento 10, foja 11. Cursivas mías para destacar la perspectiva igualitarista y su conciencia social y de clase. 
ras cinco décadas del siglo XX. A su vez, sus exigencias de equidad para las trabajadoras -al involucrarse directamente en las luchas de mujeres obreras-, se entrelazan con el reconocimiento de su propia problemática de desigualdad femenina frente a la sociedad patriarcal.

De forma individual y en colectivo las féminas constataron y sufrieron, reiteradamente, discriminación, acoso y violencia. Como se corrobora en este testimonio de Cuca García al dar a conocer el abierto desprecio, el hostigamiento y la agresión verbal de Fernando Amilpa, dirigente de la Federación Regional de Obreros y Campesinos del Distrito Federal (FROC): «El Frente Único de nosotras, donde hemos defendido a las propias mujeres de la FROC del Distrito Federal, no solamente en movimientos de huelga, sino de la [propia] traición de Amilpa y demás dirigentes, nos ha llamado el Frente Único del Plumero y de la Escoba». ${ }^{38}$

En la interacción de las comunistas con mujeres trabajadoras, ambos segmentos reconocieron la discriminación masculina de sus compañeros de lucha, tanto en los círculos partidistas como sindicales; cuyo fin fue minimizar sus determinaciones y demandas, o, de plano, ignorarlas. Amén de las expulsiones, degradaciones y depuraciones de que fueron objeto, eventualmente, por las propias instancias directivas del partido o de las dirigencias sindicales a causa de las disensiones políticas atizadas por el sectarismo y el dogmatismo.

De manera explícita o implícitamente, el patriarcado reprodujo asimétricamente la separación de los campos de acción, el reparto inequitativo de roles y las tensiones de poder entre los sexos en las organizaciones y en los compartimentos celulares.

Con infortunio, además, los cuadros femeniles fueron vilipendiados y recibieron trato de inferioridad de parte de sus dirigencias varoniles. ${ }^{39}$ Se ha corroborado la rigidez partidaria comunista y la cerrazón de su cúpula política. Aunque en sus discursos ésta se declarara en favor de la emancipación femenil. La disyuntiva se planteó constantemente para la militancia femenil: luchar al interior de su partido por la igualdad frente a sus camaradas, o desistir, viéndose obligadas a guardar la disciplina partidista en detrimento de su condición de mujeres. En distintas coyunturas sus interpelaciones y señalamientos

38 Comentarios de Refugio García sobre la actitud de la FROC y su dirigente realizados en su intervención en el VI Congreso Nacional del PCM, en Actas del VI Congreso Nacional del PCM, 23 de enero de 1937, en AHCEMOS, Colección Partido Comunista Mexicano, caja 11, clave 143, exp. 01, tomo I, 223.

39 Hernán Laborde, secretario general del PCM, debió reconocer en su VII Congreso Nacional (enero de 1939) que el partido subestimaba a los cuadros femeninos, aceptando, incluso, que se les consideraba meros objetos sexuales, y poniendo en evidencia la dificultad del conjunto partidario varonil para conceptuar a las mujeres en un plano igualitario y su incapacidad para cuestionar los estereotipos adjudicados a la belleza física femenil. Al respecto, el análisis de Olivé, Las Mujeres Comunistas en México en los años treinta, 82, es preciso y revelador: «Ese recurrir a la belleza física de la mujer, cuando ella asume un compromiso social tan importante, como es la militancia en un partido político, reproduce la connotación de símbolo sexual que la sociedad patriarcal le asigna; de hecho es una manera de devaluar su militancia». 
públicos fueron acallados y descalificados. ${ }^{40}$ «Se constata así que el género influye en aspectos como la movilización, los patrones de liderazgo, las oportunidades políticas, las estrategias, las estructuras organizativas, las ideologías e incluso los posibles impactos de un movimiento social». ${ }^{41}$

Para explicar estas inequidades de género, la historia social aporta elementos a considerar en la construcción biográfica. Por ejemplo, la visualización y la tipificación de las etapas del activismo feminista en la generación comunista de la época; condicionada por supuesto por su propia práctica política. Estamos ante una tensión que debe explicarse en el relato biográfico femenil, pues muchas comunistas retaron a la sociedad de su tiempo con su dinamismo feminista.

Si la historia de las mujeres de izquierda nos permite realizar estas puntualizaciones, estamos en la ruta de vigorizar la mirada biográfica porque aquélla nos centra en el rescate de mujeres que han sido presas de la invisibilidad, quedando relegadas y en el olvido. Por supuesto, también la (in)visibilidad de las tareas y acciones de determinados actoras tiene una explicación de género, pues «no es neutra sino jerarquizada en función de lo que socialmente se considera significativo y decisivo ${ }^{42}$ para un partido o un movimiento político, cuyas directivas con predominancia masculina acapararon, tradicionalmente, las decisiones y representaciones más visibles, realizadas en espacios destacadamente masculinizados. Olivé acota, acertadamente, que: «La permanencia, dentro del PCM, de esta visión devaluatoria de lo femenino se proyecta en la militancia de la mujer». ${ }^{43}$

Por ende, el planteamiento más consistente de la historia social de las mujeres muestra hasta dónde, con recursos innovadores, podemos argumentar y poner en valor el género femenino en el decurso de la historia. Sólo así superaremos visiones obtusas que tradicionalmente suprimieron la capacidad de las mujeres en su trasegar personal y en comunidad:

Si el prejuicio masculino ha condicionado la historiografía tanto tradicional como renovadora, la historia de la mujer se impone como estudio de aquellos campos hasta ahora poco o nada estudiados, y por lo tanto invisibles. Así el contenido de la historia cambia en cuanto buscamos a la mujer como agente histórico y nos acercaría a estas esferas donde ha habido participación de la mujer. La marginación de la mujer como objeto de estudio histórico puede comprenderse entonces a partir de un sistema de

40 Véase: Oikión Solano, V.: «Feminismo transgresor. El FUPDM y la crítica contestataria de Cuca García y Consuelo Uranga en el VI Congreso del Partido Comunista Mexicano, enero de 1937», en Núñez Becerra, F. y Ortiz Peralta, R., coords.: La osadía se viste de mujer. En el centenario de un año crucial, 1917. Secretaría de Cultura, INAH, México, 2019, 231-256. El mirador del VI Congreso Nacional del PCM nos ofrece una perspectiva en donde la formación de la izquierda comunista se trasluce como copartícipe y reproductora de las normas de género socialmente hegemónicas.

41 Martínez Hernández, E.: «Las formas de acción colectiva: partidos políticos y movimientos sociales», en Lois, M. y Alonso, A. coords., op. cit., 152.

$42 \quad$ Ibid., 155.

43 Olivé, Mujeres Comunistas en México en los años treinta, 32. 
valores y por lo tanto de una tabla de prioridades en la elección de los temas a estudiar, elección influida por el condicionamiento sexista de los historiadores. ${ }^{44}$

Justo, las posturas investigativas, desde el feminismo, «contribuyeron al giro de la historia hacia las emociones». A la par, «los avances de la psicología cognitiva y la vivaz expansión de las neurociencias [...] contribuyeron a liberar a las emociones de su extensa reclusión en la irracionalidad». El viraje paradigmático «reconoció que los procesos emocionales no son independientes de los estados cognitivos y señaló que las emociones son culturalmente específicas y se transforman, e incluso, desaparecen con el tiempo».45

La historia de las emociones -correlativa con la historia cultural y de las mentalidades- reivindica «la presencia de la dimensión afectiva en las relaciones sociales», ${ }^{46} \mathrm{y}$ nos ofrece una gradación de registros que enfatizan y ponen de relieve las pulsiones y los sentimientos en las vidas humanas, como pueden ser la amistad, el enamoramiento, la fortaleza, la tribulación, el miedo, la compasión, el encono, la turbación, la ira, la postración, el abatimiento, etcétera. A la par, nos permite adentrarnos en las tensiones psicológicas de una personalidad biografiada con respecto a sus relaciones personales y de pareja, familiares y sociales, de su círculo y núcleo más próximo, y de su entorno social, y enmarcadas todas ellas en la consecución de sus objetivos sociopolíticos. Sin dejar de poner de relieve, y de manera efectiva, la politización de lo privado.

Todo ello como parte del balance a realizar para colocar en equilibrio a una individualidad, frente a la acusada racionalidad que comúnmente se otorga a los personajes históricos; pues desde una visión poco matizada, se les considera erróneamente como de una sola pieza y con actitud impasible e inmutable. De tal manera que «la biografía permanece abierta a la expresión directa de las emociones del sujeto biografiado»; además de nutrirse de la búsqueda, interés e indagación de la esfera privada. ${ }^{47}$ Aunque siempre en relación con el agitado ambiente social y los grandes desafíos de la época en que transcurrió su experiencia vital, provocando en ella, eventualmente, sacudidas y estremecimientos emocionales, que no siempre puede expresar abiertamente -causándole verdaderas afecciones-debido a los prejuicios, los estereotipos y las ordenaciones establecidas de género.

Desde mi punto de vista, los sentimientos -como reacciones intuitivas de la mentalidad humana- pueden adicionar también la franja de registros a considerar, pues es innegable que se insertan en la historia personal de cualquier individuo y de su comportamiento específico, y en sus circunstancias particulares. El resultado pueden ser relatos biográficos sugerentes que recojan espiritualidades muy íntimas, con momentos de en-

44 Nash, M.: Mujer y movimiento obrero en España, 1931-1939. Fontamara, Barcelona, 1981, (Ensayo Contemporáneo), 11.

45 Bjerg, M.: «Una genealogía de las emociones», Quinto Sol. Revista de Historia, vol. 23, núm. 1, Universidad Nacional de La Pampa, Argentina, 2019, [3]. Disponible en: www.redalyc.org/articulo. oa? $\mathrm{id}=23157271001$. Consulta: 11 de febrero de 2020 .

46 Ibid., [4].

47 Hernández Sandoica, op. cit., 407. 
soñación y fantasía, y con alusiones a su inconsciente. Al respecto, Mary Kay Vaughan sugiere que este rescate emotivo del personaje se realice «desde su vida misma», es decir, detectar «cómo los procesos históricos afectaron su desarrollo subjetivo». ${ }^{48}$ Todo lo cual conlleva una tarea titánica de rescate, que la biógrafa o el biógrafo deberían asumir para recabar testimonios y ubicar acervos documentales y archivos personales, que justamente auxilien para documentar estas huellas emocionales.

La emotividad de una figura histórica puede, además, dar elementos para constatar en la urdimbre biográfica que lo personal es político. Intuición e introspección -presentimientos y cavilaciones femeniles íntimas- también forman parte de esta tabla contable que aúna elementos para modelar el género biográfico de mujer.

Sin olvidar en esta franja emocional lo que conlleva la maternidad, como un factor fundamental que desde la antigua tradición patriarcal se ha caracterizado como inherente a la figura femenil, es decir, como algo intrínseco a su propio sexo, por el sólo hecho de ser mujer. Este constructo social que impone los roles de esposa y madre, como marca de identidad, la obliga socialmente a demostrar regocijo perpetuo y plenitud personal, pero supone en la realidad, con frecuencia, tristeza, agobio y sufrimiento. Las limitaciones económicas exacerbadas -sin fuentes laborales estables- la pobreza prolongada, y la violencia machista intrafamiliar, amén de las presiones, las persecuciones y las represiones políticas, constriñeron el ánimo de las mujeres militantes, de sus hijos y de sus familias. ${ }^{49}$

Estas circunstancias de apremio expresan de qué manera «las emociones están cargadas de significados anclados en contextos sociohistóricos específicos, regulados por normas que definen qué debemos sentir y cómo debemos expresar lo que sentimos en una determinada circunstancia». ${ }^{50}$ La subjetividad emocional de cada mujer -con ingredientes tales como incertidumbre, angustia, desesperanza, audacia, solidaridad- fue constantemente puesta a prueba en situaciones verdaderamente dramáticas: «La tragedia de nosotras, quedé azorada de tanta cosa. Pero sí estaba dispuesta a defender al proletariado, de todo corazón. Todo lo hicimos de corazón, y por disciplina [...]. Creímos que estábamos cambiando al mundo [...]. Qué dolor, qué desilusión».51

La aproximación biográfica definitivamente debe amplificarse tomando en cuenta este abanico de atributos que conlleva la afectividad y las aflicciones de una vida militante.

48 Vaughan, M. K.: «La labor creativa en la construcción biográfica: el equilibrio entre el sujeto histórico y su contexto histórico», en Bazant, M., coord.: Biografía. Modelos, métodos y enfoques, prólogo de Enrique Krauze. El Colegio Mexiquense, 2013, 69.

49 El testimonio de Julia Barradas Hernández ejemplifica un estado de conmoción, y es conmovedor al respecto: «Tengo sólo una hija, tuve tres, el primero murió antes de que naciera la niña, el tercero se me murió de hambre. No le exagero, así dice el certificado del doctor. Estaba yo sola, a él [su pareja y militante del partido] lo habían mandado a una comisión, y no tenía ni para comer». Entrevista realizada a Julia Barradas por Natura Olivé, y citada en Olivé, Mujeres Comunistas en México en los años treinta, 89.

50 Bjerg, M., op. cit., [5].

51 «Palabra de Mujer. Una entrevista con Margarita Gutiérrez Velasco» realizada por Natura Olivé, octubrediciembre de 1988, y reproducida en Olivé, Mujeres Comunistas en México en los años treinta, 112. 
Para ellas participar en el PCM no era sólo ir a reuniones, o repartir volantes, para ellas la militancia tenía una dimensión más profunda, ocupaba un amplio espacio de su cotidianidad. Su relación de pareja [...] la establecían con militantes comunistas, en esta relación pesaba también la condición de militante de él. Ellas podían mantener al marido, ganar el sustento familiar cuando ellos estaban enfermos, porque esto era parte de una actitud solidaria [de amor, fidelidad y fraternidad], originada en la militancia. ${ }^{52}$

Esa emotividad contiene, además, una carga heroica y entrañable al exhortar a las «camaradas» -en tanto comunidad emocional- $-^{53}$ a la organización de las mujeres como «una tarea precisa e inmediata no sólo de los comunistas sino de todo aquél que se precie de amar a la humanidad, la libertad y la democracia». ${ }^{54}$

Los trabajos organizativos en conjunto con un mismo fin pueden develar la resiliencia personal construida para aminorar el desaliento frente a la adversidad, y para recargar los ánimos de voluntad individuales -vitalidad, resistencia, energía- para la acción, que le dan sentido a su propia vida política y militante. La dimensión de la capacidad adaptativa emocional y su regulación, también podría ser un elemento a considerar para detallar sus expresiones en la configuración biográfica femenina.

En el caso de las mexicanas de izquierda, su vitalidad fue tan intensa que contiene numerosos alientos empuñados constantemente como sus armas transformadoras para darse a sí mismas el valor y poder transmitir su coraje como gestoras de sus propias rutas existenciales..$^{55}$

\section{ESCRIBIENDO VIDAS}

Todo lo dicho, en su amplitud, centra el reto metodológico que supone realizar escritura de vidas, retomando la enunciación de Plutarco, el autor clásico, quien afirmó: «No escribimos historias, sino vidas». ${ }^{56} \mathrm{Si}$ miramos en perspectiva cómo ha ido evolucionando el bagaje argumental de escudriñar en la vida de otro, y más específicamente, de otra, desde lo clásico a la actualidad, el giro biográfico, con acentuación femenil, contiene la representación de una vida de mujer mediante el lenguaje escrito; realizada, generalmente, por

$52 \quad$ Ibid., 90.

53 En esta tesitura colectiva, efectivamente nos podemos apoyar en el concepto de comunidad emocional formulado por Rosenwein, y que alude a los conglomerados en los cuales sus simpatizantes o afiliadas/ os se adhieren a las mismas regulaciones de expresión emocional, y valoran -o desestiman- emociones iguales o relacionadas. Véase: Rosenwein, B. H.: Emotional Communities in the Early Middle Age. Cornell University, E.U.A, 2006, 2.

54 «Partido Comunista de México. Secc. De la I.C. Instructivo para el trabajo femenil que servirá de orientación a los organizadores del Partido que salgan a los Estados, México, D.F., enero 12 de 1938. Comisión Nacional Femenil por la Responsable Consuelo Uranga», en AHCEMOS, Colección PCM, caja 12, clave 10, exp. 1. Cursivas mías.

55 Como lo pude constatar en la realización de la biografía de Cuca García, op. cit., 365.

56 Plutarco: Vidas paralelas. Librería de A. Mézin, París, 1847, tomo III, 175. 
mujeres historiadoras, quienes «han organizado aquella experiencia [personal, individual, única] en torno a una serie de ideas-fuerza, de focos o ideales políticos o intelectuales». ${ }^{57}$

En esencia, detrás de ello se encuentra una progresiva democratización de la historia; $y$, entre otros procesos medulares, han influido las grandes movilizaciones sociales mundiales a partir de los años sesenta y setenta del siglo XX, en cuyos puntos de encuentro distintos sectores femeniles y feministas disputaron y exigieron nuevos papeles igualitarios (en los órdenes personales, sexuales, sociales, políticos, etcétera) y más protagonismo en las transformaciones de la sociedad.

Siguiendo a Sonya Rose,$^{58}$ constatamos que, a partir de todo lo dicho, nos enfrentamos a cambios y desafíos en la práctica histórica, y, sobre todo, a las maneras que podemos establecer como innovadoras al abordar la esfera privada y la esfera pública, así como su interacción en la trayectoria de una vida. Aparece entonces el cuestionamiento obligado de: «¿Cuál es el reto que enfrenta el biógrafo o la biógrafa que desea investigar y escribir la vida de una mujer?» ${ }^{59}$

El desafío es formidable y profundo, pues no sólo es colocar en el centro a la fémina biografiada, sino conservar una línea de equilibrio entre la revelación de la especificidad de su vida, y la carga de su tiempo y circunstancia históricos, es decir, mantener un balance con respecto a su contexto y sus enlaces sociales, comunitarios y colectivos, para que su estatura biográfica -toma de decisiones definitorias de su trayectoria y afirmación de su personalidad- no se diluya o se resbale irremediablemente por los márgenes de un relato a-histórico o con simpleza cronológica.

Metodológicamente esta escritura de vidas representa un acentuado desafío, como ya lo ha planteado el historiador Carlos Herrejón:

En el caso de las biografías, el problema es mayor porque toda persona, objeto de búsqueda, es singularmente inagotable e inasible [...]. Tengo para mí que la clave para entender y organizar una biografía es buscar las decisiones más trascendentes, las que orientan los principales periodos de la vida, las que redefinen las relaciones familiares, amorosas, laborales, profesionales, morales, religiosas, etcétera, de tal manera que las acciones posteriores de la persona generalmente son consecuencia de la resolución primordial. Funcionan como goznes que van armando la estructura biográfica a través del tiempo. ${ }^{60}$

Por ende, el viraje biográfico notable se vigoriza al erigir una vida que transita y apuntala su propia realidad histórica; una singularidad enmarcada en su tiempo y en su

57 Hernández Sandoica, op. cit., 421.

58 Rose, Sonya O.: ¿Qué es historia de género?, traducción de Noelia Adánez González. Alianza editorial, Madrid, 2012, 21.

59 Chassen-López, F.: «Mitos, mentiras y estereotipos: el reto de la biografía feminista», en Bazant, M., coord., op. cit., 149.

60 Herrejón Peredo, C.: «Buscando los goznes en la biografía de Hidalgo», en Bazant, M. coord., op. cit., 44. 
espacio propio. Además, si utilizamos la evocación, la recreación y la imaginación (con suposiciones e inferencias consistentes y sólidas) como instrumentos para la definición del itinerario de una existencia, estaremos en la posibilidad de seguir las huellas de su integridad y, por tanto, explicarla desde lo social y lo político, y sobre todo, desde su humanidad femenina, a la luz, precisamente, de su realidad concreta. Lo que Chassen-López ha llamado «restaurar a la mujer en la historia», ${ }^{61}$ es decir, metafóricamente, proyectando el haz luminoso de una mujer vívida, y en su línea de fuego, y a su alrededor a miles más de carne y hueso, inconformes, visionarias y sensibles, y, por supuesto, batallando contra los desafíos impuestos por las estructuras sociales desiguales y autoritarias y contra los rangos de género.

En este tenor, para el caso mexicano, tenemos afiliadas a la izquierda que traspasaron los estereotipos de su época, refutaron el predominio de la jerarquía del sistema patriarcal (incluso al interior del propio Partido Comunista), ${ }^{62}$ y se convirtieron en puentes difusores y correas de transmisión de ideas socialistas, y a la vez propagandistas del pensamiento opositor en favor de la transformación creadora (por ejemplo, fue el caso de las profesionales comunistas con acentuación social -médicas, abogadas, maestras-, y aquéllas con vocaciones culturales y artísticas).

La coyuntura clave, y más relevante, que alentaron todas ellas en conjunto, fue su capacidad de aglutinamiento en el Frente Único Pro Derechos de la Mujer (FUPDM). La masiva organización unitaria femenina -incluyente, interpartidista e interclasista- hegemonizada precisamente por el núcleo femenil comunista, y acrecentada -aglutinó alrededor de cien mil mujeres- a la vera de la intensa movilización popular impulsada por el gobierno de Lázaro Cárdenas en la segunda mitad de los años treinta. En ese ámbito tan peculiar, inédito y sorprendente, como la máxima expresión del movimiento femenil mexicano más destacado de la primera mitad del siglo XX, sobresalieron mujeres muy valientes que hasta hoy en día están a la espera de la escritura de sus semblanzas de vida.

\section{COMENTARIOS FINALES: EL FELIZ ENCUENTRO DE LAS MUJERES DE IZQUIERDA Y EL GIRO BIOGRÁFICO}

En definitiva, como se ha mostrado aquí, la reestructura del paradigma biográfico es una revolución conceptual y argumental que, a manera de novedosa atalaya analítica, nos provee de un baremo instrumental con el propósito de comenzar a darles visibilidad a cientos de mujeres que se asumieron de izquierda en su accionar personal y colectivo. Las

61 Chassen-López, «Mitos, mentiras y estereotipos», en Bazant, M. coord., op. cit., 150.

62 El testimonio de Adelina Zendejas resulta elocuente al respecto: «Las mujeres revolucionarias militantes del PC hemos tenido que combatir más los prejuicios y la discriminación dentro del partido que afuera con la burguesía». Revísese: Zendejas, A.: «No nos detenía nada», en García Flores, M.: ¿Sólo para mujeres? Y en medio de nosotras el macho como un dios. Radio Universidad Nacional Autónoma de México, México, 1979, 35. 
premisas planteadas dejan al descubierto las lagunas y las proscripciones en torno de la configuración de perfiles biográficos femeninos como fundamentos nutrientes de la historia de las mujeres en México, y de manera particular de aquéllas de la izquierda militante. John Mraz ha dicho con razón que: «Enterrada bajo las proclamas, las declaraciones y los discursos de los cuerpos gobernantes compuestos por hombres encontramos escondida la historia de las mujeres». ${ }^{63}$

La indagación en la vida de una mujer y la erección de su biografía pasan también por sacarla del olvido y darle un rostro memorístico; más en el caso de las mujeres de izquierda que durante muchas décadas han permanecido en las sombras y al margen de la historia. Lo aquí planteado reafirma que esas individualidades bien pueden rescatarse de los marginales bordes sociohistóricos.

De tal suerte que la propuesta trazada también va en el sentido de superar la insuficiencia de biografías de féminas de izquierda de la primera mitad del siglo XX. El vuelco biográfico encara, por ende, la tensión continuada entre omisión, silencio e historia. En el camino de extraer esas historias obliteradas, necesariamente también es obligado enfrentar los vacíos documentales y buscar y rebuscar fuentes perdidas, sobre todo, testimonios que rescaten las voces femeniles hasta ahora sepultadas. Y como tal ha sido expresado por Chassen-López: «la biógrafa de una mujer tiene que ser emprendedora e imaginativa para encontrar sus fuentes [...] no puede escapar de la contrariedad que representa lo fragmentario de los datos». ${ }^{64}$

Su afirmación coincide con el señalamiento de Perrot: «Para escribir la historia hacen falta fuentes, documentos, huellas. Y esto constituye una dificultad en la historia de las mujeres. Su presencia suele estar tachada, sus huellas borradas, sus archivos destruidos». ${ }^{65}$

En el caso mexicano, las fuentes están dispersas en fondos poco conocidos. Menciono sólo algunos: el AHCEMOS, organismo que resguarda el patrimonio documental de la izquierda comunista en México. El repositorio privado del activista Gerardo Peláez Ramos. El Fondo documental del general Francisco José Múgica Velázquez y el Fondo documental de la doctora Mathilde Rodríguez Cabo, ambos en el Archivo Histórico de la Unidad Académica de Estudios Regionales de la Coordinación de Humanidades de la UNAM, localizado en la ciudad de Jiquilpan, Michoacán. El acervo de Esther Chapa, médica y comunista, en manos de sus descendientes. Amén de la hemerografía local, regional y nacional, tanto la de carácter oficial u oficioso, así como la generada por distintos grupos femeniles y de la izquierda política, y depositada en acervos no siempre accesibles. En síntesis, el acceso a los testimonios, las memorias, las autobiografías, la correspondencia, las evidencias de la acción política, para el caso de las mujeres de la

63 Mraz, J., «Más allá de la decoración: hacia una historia gráfica de las mujeres en México», Política y Cultura, núm. 1, otoño de 1992, 155.

64 Chassen-López, F.: «Biografiando mujeres: ¿qué es la diferencia?», Secuencia, op. cit., 141.

65 Perrot, op. cit., p. 25. 
izquierda, no resulta una tarea grata e inmediata. Las pistas seguidas no siempre conducen al encuentro de fuentes provechosas y útiles. Por estas razones es que también se deben detectar «los silencios» $\mathrm{y}$ «lo no dicho» por las fuentes restringidas; leer entre líneas y descubrir los empeños femeninos en lo implícito, corroborando con algún grado de certeza y de manera indirecta la presencia de las féminas mediante el entrecruzamiento y la confrontación de la información obtenida.

Por otra parte, ha quedado expresado, además, que la historia biográfica, como historia social, es una exploración y una explicación consistente para dilucidar la construcción de una personalidad y una conciencia única y precisa, y a la vez éstas como partes inherentes y esenciales de un colectivo identitario de género, es decir, asumiendo plenamente su integridad política femenina y su afinidad revolucionaria.

La ola generacional femenil de la izquierda mexicana canalizó su activismo hacia fuera de su ámbito hogareño confinado y fue pionera en la construcción de una ciudadanía crítica y en movimiento. La esencia de las vidas de estas mujeres, unidas en una biografía colectiva ${ }^{66}$ puede entonces ponderarse como lúcida, transgresora e imaginativa.

De ahí resulta que el giro biográfico creativo no es sólo la construcción de una sola figura en solitario; el acento innovador implica realzar sus méritos, sus obras y su trayectoria, engarzada a y haciéndola parte de su agrupación, comunidad y colectividad -al construir señaladamente redes de apoyo y sociabilidades políticas- ante los grandes desafíos de su tiempo. Y enfatizando su interpelación del orden dominante sexista patriarcal de muy diversas maneras para reivindicar sus derechos civiles, sociales y políticos.

Las biografías que retornan ahora, masivamente, muestran en toda su panoplia aquella pluralidad de horizontes que viene de sumar influjos colectivistas (procedentes de las ciencias sociales) y el rescate de la singularidad. Dos influencias pues, claramente antagónicas, que originan productos historiográficos del todo diferentes, desde la biografía política individual hasta la prosopografía pasando por la sociología histórica, que también ofrece acogida a cierto tipo de biografías plurales como uno de sus capítulos de actividad. ${ }^{67}$

El caso específico del género biográfico de mujer, últimamente con gran impulso en México, ${ }^{68}$ como lo ha constatado Chassen-López,

66 Un caso de biografía colectiva, es la obra coral de María Teresa Fernández Aceves, Mujeres en el cambio social en el siglo XX mexicano. Siglo XXI Editores y CIESAS, México, 2014.

67 Hernández Sandoica, op. cit., 414.

68 De una década a la fecha se han multiplicado las publicaciones que se afincan en el giro biográfico, aunque no todas atienden mujeres de la izquierda. Lo relevante es que ha fructificado la intención historiográfica de poner atención a las historias de mujeres con perspectiva analítica de género. Sólo para ejemplificar menciono algunas: Cano, G.: Se llamaba Elena Arizmendi. Tusquets, México, 2010, (Colección Centenarios, 8). Lau Jaiven, A. y Mc Phail Fanger, E. coords.: Rupturas y continuidades. Historia y Biografías de Mujeres. Universidad Autónoma Metropolitana Unidad Xochimilco, México, 2018. Núñez Becerra, F. y Ortiz Peralta, R. coords.: La osadía se viste de mujer. En el centenario 
muestra una capacidad analítica y una sofisticación admirables. La realización de investigaciones profundas, que utilizan una diversidad de fuentes, la preocupación por nuevos temas y el uso de nuevos métodos han permitido [...] zanjar algunos de los retos y obstáculos particulares que enfrenta la biógrafa de una mujer. Consecuentemente, estas nuevas biografías están restableciendo a la mujer mexicana, como sujeto y agente histórico, en aras de animar una transformación de cómo se escribe la historia mexicana. ${ }^{69}$

Finalmente, debo subrayar que la nueva mirada biográfica -abarcando sus usos con énfasis de género- nos ofrece la capacidad hermenéutica de dar relieve al pasado unipersonal femenino, enmarcando a un ser vital como actora social y como sujeta histórica. Esta sustancialidad humana y única se aprecia con creces al reflexionar analíticamente sobre vida e historia.

de un año crucial, 1917. Secretaría de Cultura, INAH, 2019, (Colección Historia, Serie Logos). Rashkin, E. y Hernández Palacios, E. coords.: Luz rebelde. Mujeres y producción cultural en el México posrevolucionario. Universidad Veracruzana, México, 2019.

69 Chassen-López, F.: «Biografiando mujeres: ¿qué es la diferencia?», Secuencia, op. cit., 157-158. 


\section{BIBLIOGRAFÍA}

Bjerg, María (2019), «Una genealogía de la historia de las emociones», en Quinto Sol. Revista de Historia, vol. 23, $\mathrm{n}^{\circ}$ 1, Universidad Nacional de La Pampa, Argentina.

Burdiel, Isabel (ed.) (2014), «Presentación» dossier «Los retos de la biografía», en Ayer, $\mathrm{n}^{\circ} 93(1), \mathrm{pp} .13-18$.

Burdiel, Isabel (2016), «¿Qué Biografía para qué Historia? Conversación con Isabel Burdiel y María Sierra», en: Gallego, Henar y Mónica Bolufer (eds.), ¿Y ahora qué? Nuevos usos del género biográfico. Barcelona, Icaria editorial, (Historia y Feminismo, 10), pp. 19-35.

Cano, Gabriela (1993), «Adelina Zendejas: arquitecta de su memoria», en Debate feminista, año 4, vol. 8, pp. 387-400.

Cano, Gabriela (2007), «Las mujeres en el México del siglo XX. Una cronología mínima», en: Lamas, Martha (coord.), Miradas feministas sobre las mexicanas del siglo XX. México, Fondo de Cultura Económica y Conaculta, pp. 21-75.

Cano, Gabriela (2010), Se llamaba Elena Arizmendi. México, Tusquets (Colección Centenarios, 8).

Carlyle, Thomas (2006), Biografía. México, UNAM (Colección Pequeños Grandes Ensayos, 43).

Chassen-López, Francie (2013), «Mitos, mentiras y estereotipos: el reto de la biografía feminista», en: Bazant, Mílada (coord.), Biografía. Modelos, métodos y enfoques, prólogo de Enrique Krauze. México, El Colegio Mexiquense, pp. 149-178.

Chassen-López, Francie (2018), «Biografiando mujeres: ¿qué es la diferencia?», en Secuencia, revista de historia y ciencias sociales, Instituto «Dr. José María Luis Mora», $\mathrm{n}^{\circ} 100$, pp. 133-162.

Condés Lara, Enrique (2015), Atropellado amanecer. El comunismo en el tiempo de la Revolución Mexicana. México, Benemérita Universidad Autónoma de Puebla.

Dosse, François (2007), El arte de la biografía. Entre historia y ficción. México, Departamento de Historia de la Universidad Iberoamericana (El Oficio de la Historia).

Fernández Aceves, María Teresa (2014), Mujeres en el cambio social en el siglo XX mexicano. México, Siglo XXI Editores y CIESAS.

González Bustos, Marcelo (2017), Historia de una mujer comunista. Benita Galeana Lacunza. México, Universidad Autónoma Chapingo.

Hernández Sandoica, Elena (2004), Tendencias historiográficas actuales. Escribir historia hoy. Madrid, Akal Universitaria, (Serie Historia Contemporánea, 234).

Herrejón Peredo, Carlos (2013), «Buscando los goznes en la biografía de Hidalgo», en: Bazant, Mílada (coord.), Biografía. Modelos, métodos y enfoques, prólogo de Enrique Krauze. México, El Colegio Mexiquense, pp. 41-52.

Lau Jaiven, Ana (2009), «Las luchas por transformar el estatus civil de las mexicanas: las organizaciones pro sufragio femenino 1919-1930», en: Cárdenas, Nicolás y Enrique Guerra Manzo (coords.), Integrados y marginados en el México posrevolucionario. 
Los juegos de poder local y sus nexos con la política nacional. México, Universidad Autónoma Metropolitana Unidad Xochimilco y Miguel Ángel Porrúa Editor, pp. 297-347.

Lau Jaiven, Ana y Elsie Mc Phail Fanger (coords.) (2018), Rupturas y continuidades. Historia y Biografías de Mujeres. México, Universidad Autónoma Metropolitana Unidad Xochimilco.

Martínez Hernández, Eva (2014), «Las formas de acción colectiva: partidos políticos y movimientos sociales», en: Lois, Marta y Alba Alonso (coords.), Ciencia política con perspectiva de género. Madrid, Akal, (Akal Textos, 38), pp. 129-159.

Mraz, John (1992), «Más allá de la decoración: hacia una historia gráfica de las mujeres en México», en Política y Cultura, ${ }^{\circ}$ 1, pp. 155-189.

Muñoz Fernández, Ángela y Ma Dolores Ramos Palomo (2009), «Mujeres, política y movimientos sociales. Participación, contornos de acción y exclusión», en: Borderías, Cristina (ed.), La Historia de las Mujeres. Perspectivas actuales. Barcelona, Asociación Española de Investigación en Historia de las Mujeres e Icaria editorial, (Historia y Feminismo, 2), pp. 69-131.

Nash, Mary (1981), Mujer y movimiento obrero en España, 1931-1939. Barcelona, Fontamara (Ensayo Contemporáneo).

Núñez Becerra, Fernanda y Rina Ortiz Peralta (coords.) (2019), La osadía se viste de mujer. En el centenario de un año crucial 1917. México, Secretaría de Cultura, INAH (Colección Historia. Serie Logos).

Oikión Solano, Verónica (2017), «Un atisbo al pensamiento y acción feministas de la doctora Mathilde Rodríguez Cabo», en Relaciones. Estudios de Historia y Sociedad, vol. XXXVIII, n 149, El Colegio de Michoacán, pp. 101-135.

Oikión Solano, Verónica (2018), Cuca García (1889-1973), por las causas de las mujeres y la revolución, prólogo de Mary Kay Vaughan. Zamora, El Colegio de Michoacán y El Colegio de San Luis (Colección Investigaciones).

Oikión Solano, Verónica (2019), «Las comunistas mexicanas, herederas de revoluciones», en Memoria. Revista de Crítica Militante, n² 272, año 2019-4, pp. 19-25.

Oikión Solano, Verónica (2019), «Feminismo transgresor. El FUPDM y la crítica contestataria de Cuca García y Consuelo Uranga en el VI Congreso del Partido Comunista Mexicano, enero de 1937», en: Núñez Becerra, Fernanda y Rina Ortiz Peralta (coords.), La osadía se viste de mujer. En el centenario de un año crucial, 1917. México, Secretaría de Cultura, INAH, pp. 231-256.

Olcott, Jocelyn (2009), «Take off that Streetwalker's Dress. Concha Michel and the Cultural Politics of Gender in Postrevolutionary Mexico», en Journal of Women's History, vol. 21, n³, pp. 36-59.

Olivé, Natura (1991), «Las mujeres en el Partido Comunista Mexicano. Los años treinta». México, Tesis de maestría en Historia, Escuela Nacional de Antropología e Historia, División de Estudios Superiores, Programa de Maestría en Historia y Etnohistoria. 
Olivé, Natura (2014), Mujeres Comunistas en México en los años treinta. México, Ediciones Quinto Sol.

Pereira Fernández, Alexander (2011), «Notas para jugar con la ilusión biográfica y no perderse en el intento», en Revista Científica Guillermo de Ockham, Universidad de San Buenaventura, vol. 9, $\mathrm{n}^{\circ}$ 1, pp. 105-122.

Perrot, Michelle (2009), Mi historia de las mujeres, traducción de Mariana Saúl. Buenos Aires, Fondo de Cultura Económica (Sección de Obras de Historia).

Plutarco (1847), Vidas paralelas, tomo III. París, Librería de A. Mézin.

Poniatowska, Elena (1992), Tinísima. México, Ediciones Era.

Porter, Susie S. (2018), «Otilia Zambrano Sánchez de García, cambio generacional y activismo en las décadas de 1920 y 1930», en: Lau Jaiven, Ana y Elsie Mc Phail Fanger (coords.) Rupturas y continuidades. Historia y Biografías de Mujeres. México, Universidad Autónoma Metropolitana Unidad Xochimilco, pp. 171-197.

Rashkin, Elissa J. y Ester Hernández Palacios (coords.) (2019), Luz rebelde. Mujeres y producción cultural en el México posrevolucionario. México, Universidad Veracruzana (Colección Biblioteca).

Rose, Sonya O. (2012), ¿Qué es historia de género?, traducción de Noelia Adánez González. Madrid, Alianza editorial.

Rosenwein, Barbara H. (2006), Emotional Communities in the Early Middle Age. Ithaca y Nueva York, Estados Unidos, Cornell University Press, 2006.

Sánchez Quintanar, Andrea (2003), «La historiografía mexicana de izquierda», en: Hernández, Conrado, Tendencias y corrientes de la historiografía mexicana del siglo $X X$. Zamora, El Colegio de Michoacán e Instituto de Investigaciones Históricas de la UNAM, (Colección Debates), pp. 91-119.

Sierra, María (2016) «¿Qué Biografía para qué Historia? Conversación con Isabel Burdiel y María Sierra», en: Gallego, Henar y Mónica Bolufer (eds.), ¿Y ahora qué? Nuevos usos del género biográfico. Barcelona, Icaria editorial, (Historia y Feminismo, 10), pp. 19-35.

Tavera, Susanna (2016), «¿Escribir sobre una vida o sobre muchas? Vida, escritura e historia: la política de las biografías de mujeres», en: Gallego, Henar y Mónica Bolufer (eds.), ¿Y ahora qué? Nuevos usos del género biográfico. Barcelona, Icaria editorial, (Historia y Feminismo, 10), pp. 149-175.

Vargas Valdés, Jesús (2017), Consuelo Uranga. La roja. Chihuahua, Nueva Vizcaya editores.

Vaughan, Mary Kay (2013), «La labor creativa en la construcción biográfica: el equilibrio entre el sujeto y su contexto histórico», en: Bazant, Mílada (coord.), Biografía. Modelos, métodos y enfoques, prólogo de Enrique Krauze. México, El Colegio Mexiquense, pp. 55-76.

Vilanova Ribas, Mercedes (2016), «Debate. Mesa Redonda: Vidas contadas. Biografía e Historia Oral», en: Gallego, Henar y Mónica Bolufer (eds.), ¿Y ahora qué? Nuevos 
usos del género biográfico. Barcelona, Icaria editorial, (Historia y Feminismo, 10), pp. 241-255.

Zendejas, Adelina (1979), «No nos detenía nada», en: García Flores, Margarita, ¿Solo para mujeres? Y en medio de nosotras el macho como un dios. México, Universidad Nacional Autónoma de México, pp. 27-39. 